\title{
Artwork
}

\section{Sealskin Flowers in the Forest}

\author{
Lauren Young 1 \\ 1Dalhousie University \\ DOI: https://doi.org/10.15273/hpj.v1i2.11196
}
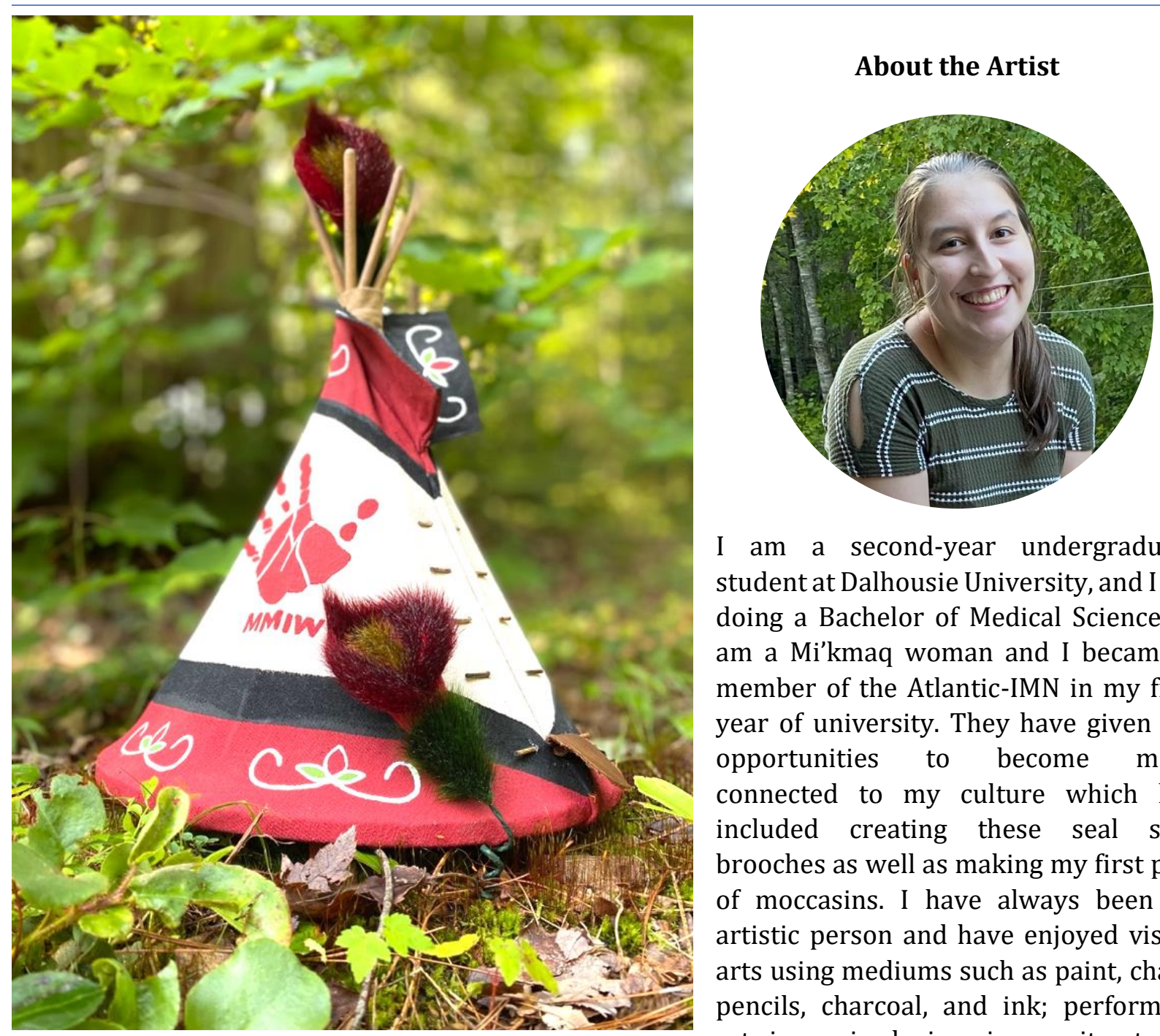

I am a second-year undergraduate student at Dalhousie University, and I am doing a Bachelor of Medical Sciences. I am a Mi'kmaq woman and I became a member of the Atlantic-IMN in my first year of university. They have given me opportunities to become more connected to my culture which has included creating these seal skin brooches as well as making my first pair of moccasins. I have always been an artistic person and have enjoyed visual arts using mediums such as paint, chalk, pencils, charcoal, and ink; performing arts in music playing piano, guitar, tenor saxophone, and baritone saxophone. Having the opportunity to work on making brooches and moccasins has enabled me to explore a new form of art that made me feel more connected to natural elements within our world that are provided to us. The IMN gives a chance to step away from academics and connect with a community of people who share similar values and culture but varied life experiences. Despite COVID-19, they still offered an opportunity to connect virtually, and share knowledge and learnings. It is a great group and I look forward to future events as well as the chance to meet other members in person! 